Sharif University of Technology
Scientia Iranica
Transactions E: Industrial Engineering
hCIENTIA

\title{
Humanitarian relief supply chain performance evaluation by a SCOR based Trapezoidal type-2 fuzzy multi-criteria decision making methodology: An application to Turkey
}

\author{
E. Ayyildiz* and A. Taskin \\ Department of Industrial Engineering, Yildiz Technical University, 34349 Istanbul, Turkey \\ Received 1 January 2019; received in revised form 10 October 2020; accepted 9 November 2020
}

\author{
KEYWORDS \\ Humanitarian relief \\ supply chain; \\ SCOR; \\ Performance \\ evaluation; \\ Trapezoidal type-2 \\ fuzzy numbers; \\ AHP.
}

\begin{abstract}
Determining the most important criteria to evaluate the performance of a Humanitarian Relief Supply Chain (HRSC) is aimed in this study. For this purpose, the Supply Chain Operations Reference (SCOR) model was adapted in the HRSC. A trapezoidal Type-2 Fuzzy Analytic Hierarchy Process (T2F-AHP) methodology was developed to evaluate the criteria influencing the performance of the HRSC as well as the performance of different Non-Governmental Organizations (NGOs) operating in Turkey as a real case study. Results of this methodology can be used by both governmental and NGOs to improve their HRSC strategies. The results underwent a sensitivity analysis to identify the feasibility and applicability of the proposed methodology.
\end{abstract}

(C) 2022 Sharif University of Technology. All rights reserved.

\section{Introduction}

Supply chain generally connects the sources of supply to the owners of demand. The main goal of supply chains is to deliver the right supplies in the right quantities to the right places at the right time [1]. Supply chains include all processes and activities associated with the transformation and flow of goods from the raw material through the end customer [2]. A Humanitarian Relief Supply Chain (HRSC) is defined as a network created through the flow and transformation of supplies, services, finance, and information between suppliers, donors, and beneficiaries of humanitarian organizations to provide aid to beneficiaries [3]. Similar

*. Corresponding author. Tel.: +90212 3832865 E-mail address: ertugrulayyildiz@ktu.edu.tr (E. Ayyildiz)

doi: $10.24200 /$ sci. 2020.52592 .2786 to a regular supply chain, HRSC starts from the donation and finishes at the point of end consumers.

Although there is more than one type of HRSC, a typical HRSC is given Figure 1 [4]. The main parties in the HRSC are governmental and Non-Governmental Organizations (NGOs) [5]. Governments have power to enact or enforce laws. They can control the economic and political conditions with the power they hold. Thus, they affect all processes of the HRSC with their decisions and practices. Other significant players in the HRSCs are public and private organizations, donors, and beneficiaries. Donors become particularly influential in prompting humanitarian organizations to think in terms of greater donor accountability and transparency of the whole supply chain [6].

Humanitarian organizations were among the first NGOs founded. They were generally faith-based organizations. These NGOs may be active in different areas such as working to save lives of malnourished children, 


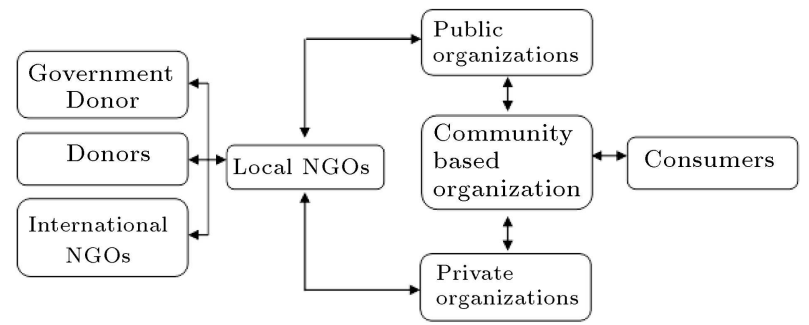

Figure 1. A traditional humanitarian supply chain [4].

ending poverty and saving lives, achieving social justice, assisting populations in distress, helping people affected by war, assisting those in urgent need of firstresponse health care and related emergency services, and carrying out humanitarian relief operations to help victims of disasters.

HRSC is not usually stable, although the structure of HRSCs is similar to general supply chains [7]. Therefore, management and coordination of HRSC is a basic requirement. The goals, performance criteria, and income sources of human and business supply chains are different. Unlike the business supply chains, HRSCs do not have any profit goals. As the regular supply chains rely on stakeholders, HRSC relies on volunteers and donors. The sources of revenue for HRSCs are government funding, donations from corporations or individuals, and in-kind donations. The goal of HRSC is to be able to respond to multiple interventions as quickly as possible and within a short time frame [6]. Studies in the field of HRSC and its extensions are increasing. Sheu worked on the challenges of emergency logistics management by focusing on disasters in the world [8]. Ge et al. evaluated the post disaster plan of China's government [9]. Khan and Salman worked on the spatial pattern of vulnerability to climate change hazards in Pakistan by developing a human vulnerability index [10]. Özdamar and Demir described a hierarchical cluster and route procedure for coordinating vehicle routing in large-scale post-disaster distribution and evacuation activities [11]. Alexander et al. performed a successful analysis that focused on risk identification, analysis, and assessment: a dynamic household economy [12]. Wang et al. constructed a nonlinear integer open location routing model for a relief distribution problem and tested their model in real case [13]. Liu et al. worked on both deterministic and stochastic medicine logistics planning models by using a time-space network approach [14]. Singh et al. proposed a big-data analytics-based approach that considered Twitter data for the identification of supply chain management issues in food industries [15]. Gharib et al. used a three-stage approach to solving an emergency vehicle routing problem in disaster [16]. According to Balcik and Beamon [17], performance evaluation in the non-profit sector includes immeasurability of the missions; intangibility of the services of- fered; unknowable outcomes; and the variety, interests, and standards of stakeholders. Tatham and Kovacs aimed to understand the swift trust in hastily formed networks as a means of improving relief operations in rapid onset disasters [18]. Swift trust model and its conditions were examined in their work. Blecken developed a process reference model, which aimed to support humanitarian organizations by designing appropriately adapted supply chain processes in order to support their operations, visualize their processes, measure their performance and thus, improve communication and coordination of organizations [19]. Van der Laan et al. pointed out that the biggest challenges in evaluating performance were data accuracy and that the performance indicators in hand were not geared towards future improvement [20]. Kabra and Ramesh worked on a disaster in India to investigate the obstacles and solutions ahead of the coordination [21]. Then, they used the fuzzy AHP technique to find solutions for overcoming the barriers.

Anjomshoae et al. aimed to identify the conceptual interdependencies among key performance indicators and represented them in the form of a conceptual model for HRSC [22]. Lu et al. applied the Supply Chain Operations Reference (SCOR) framework to the context of humanitarian supply chains and identified the most important metrics through examining the supply chain processes [23]. Laguna-Salvadó et al. developed an algorithm to solve a multi-objective problem, which aimed to support the tactical planning of the sustainable HRSC [24]. Roh et al. identified the key factors in selecting humanitarian relief warehouse location as criteria in the AHP [25]. Drakaki et al. developed an intelligent multi-agent system, which used a fuzzy AHP extended with risk factors to address a refugee settlement site planning decision making problem [26].

Humanitarian challenges are arising from famines, civil wars, and natural disasters. The Middle East region hosts the populations that are among the most vulnerable to humanitarian crises in the world. As an instance, Turkey, which is our area of interest (Figure 2 ), has become home to many war victims.

In such a context, supporting NGOs to manage, procure, and distribute aid is crucial. In this paper, three important NGOs operating in Turkey were considered to evaluate their supply chain performances by the proposed SCOR-based trapezoidal Type-2 Fuzzy (T2F) Multi-Criteria Decision Making (MCDM) methodology.

The literature on HRSC was reviewed to determine and define performance indicators for NGOs based on the SCOR model. Data was collected from different humanitarian relief organizations in Turkey to evaluate NGOs. Then, data was analyzed and Type-2 Fuzzy-Analytic Hierarchy Process (T2F-AHP) 


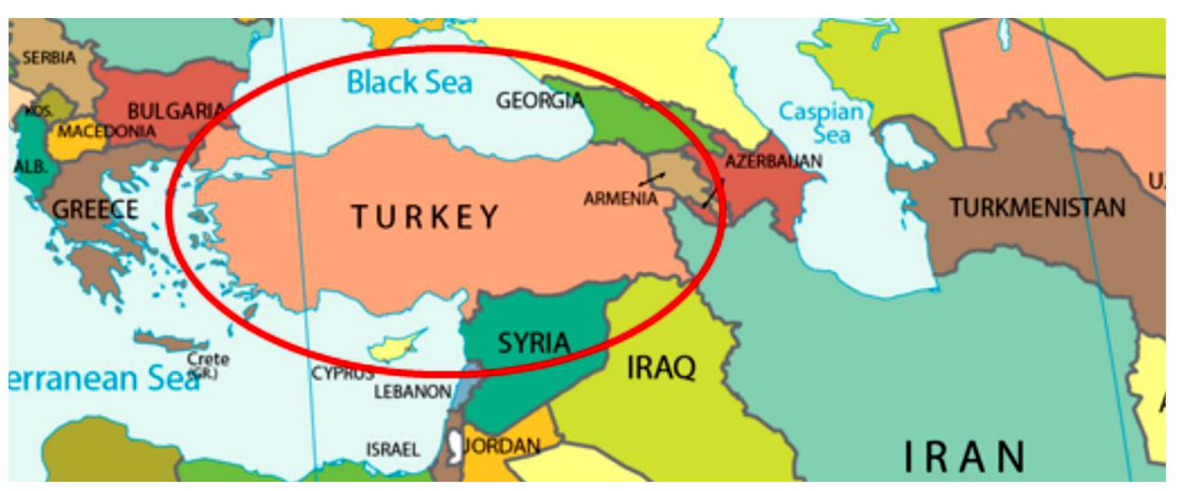

Figure 2. Turkey and its neighboring countries.

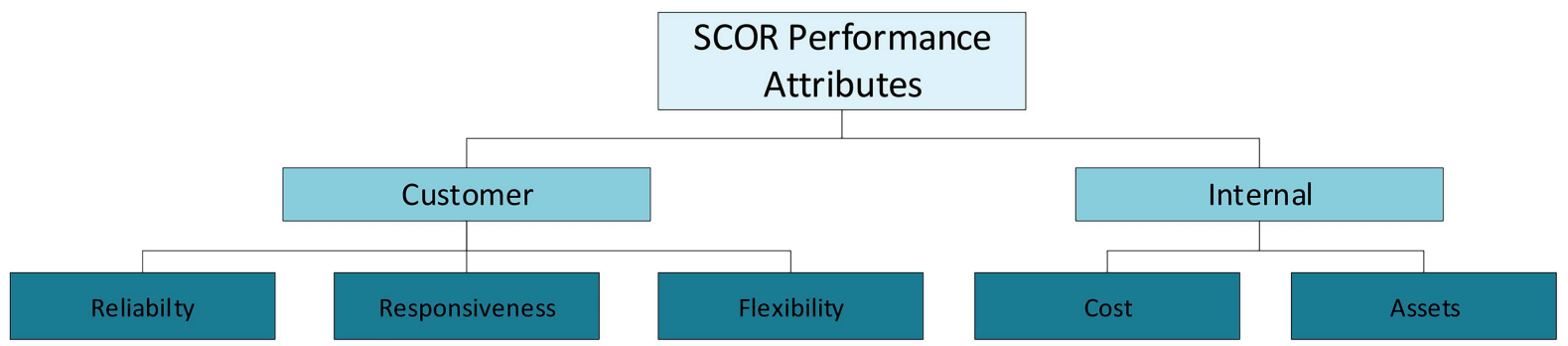

Figure 3. SCOR performance attributes.

methodology was employed to determine the most effective criteria in HRSC performance evaluation. Finally, the supply chain performances of three NGOs from Turkey were evaluated as a real case application.

Determining the most important criteria for the performance evaluation of HRSC was aimed in this study. Here, the SCOR model was modified to evaluate HRSC performances. Then, T2F-AHP was applied to evaluate the determined criteria, which influenced the performance of the HRSC. Finally, opinions of experts about the criteria were gained from three NGOs and their performances were determined.

This study is organized as follows: In Section 2, the adapted SCOR criteria hierarchy is described. The proposed MCDM methodology is presented in Section 3. In Section 4, the performances of the three NGOs are evaluated using the proposed fuzzy-MCDM methodology. Finally, Section 5 draws the conclusions, limitations, and future recommendations.

\section{The humanitarian relief SCOR model}

In 1996, Supply Chain Council (SCC) developed the SCOR model to assist companies in improving the effectiveness of their supply chains and to provide a process-based approach to the management of supply chains [27]. SCOR is a combination of benchmarking, business process reengineering, and best practices, which is considered as a reference model at an industrial standard. Standard means how a company performs, how it is configured, the way of interaction among the processes, and the requirements of the staff who operate the processed. In order to be more easily and effectively applied to the industry, the current version of SCOR has undergone continuous updating and detailing. This model is the first reference model in the world, which is recognized as the cross-industry standard for supply chain management.

There are four basic components in the SCOR reference model. These four components are described below:

- Performance: Standard metrics for defining supply chain performance and defining strategic objectives;

- Processes: Standard definitions of process relations and management processes;

- Practices: Management applications that provide better process performance;

- People: The standard for the people's skills needed to better perform the supply chain processes.

The performance part of the SCOR reference model consists of two types of components: performance attributes and metrics. Performance attributes are a group of metrics used to explain a strategy. An attribute is used to determine the strategic direction and cannot be utilized for measurement by itself. Metrics, on the other hand, measure the ability to achieve the strategic directions and are the standard for measurement. SCOR recognizes five key supply chain performance attributes, which can be seen in Figure 3: 
1. Reliability: The right distribution of the supply chain to the right customer at the right place, at the right time, in the right shape and in the right package, in the right amount, with the right documents;

2. Responsiveness: Delivery speed of the products of the supply chain to customers;

3. Agility/Flexibility: The ability of the supply chain to respond to changes in the market to maintain or enhance competitiveness;

4. Cost: All costs related to the management of the supply chain;

5. Assets: Efficiency of managing the assets of the supply chain organization to meet demand.

The SCC recommends supply chain scorecards to contain at least one metric for each performance attribute to ensure balanced decision making and governance [28]. Performance evaluation in HRSC starts from the storage of goods, materials, and information from the point of origin to the point of end customer. Efficient and low-cost processes need to be implemented in order to fulfill the objective of the supply chain, i.e., reaching for alleviating the disaster problems for the victims.

As it can be seen from the figure below (Figure 4), there are three attributes that must be directly considered for HRSC performance evaluation in terms of reliability, flexibility, and responsiveness. These performance attributes are determined based on the general SCOR model considering relief needs and agility of victims, according to the judgement of the experts on the considered three Turkish NGOs. Then, their sublevels are determined in the same way. Here, cost and asset attributes are not taken into account, because monetary subjects do not have primary importance in humanitarian relief management. The humanitarian relief SCOR model proposed in this study is shown in Figure 4.

\section{The proposed methodology}

In this study, a three-level hierarchy was established with the SCOR model attributes suitable for humanitarian relief performance evaluation as the model criteria. Then, the experts (representing each NGO) evaluated both criteria and sub-criteria. Evaluations of the experts were gained by interviews and consolidated by modified Delphi method. Subsequently, weights of the criteria were determined by the proposed T2FAHP methodology using the consolidated pairwise comparison. Then, experts from the NGOs acting in Turkey evaluated the NGO alternatives on the basis of these criteria. Lastly, sensitivity analysis was performed to emphasize the results of the proposed methodology. Steps of the proposed methodology are given in Figure 5 and detailed in following sub-sections.

\subsection{The modified Delphi method}

To consult multiple experts can be necessary to gain different opinions from different points of view on a particular topic. The Delphi method can be employed to consolidate these opinions. The method analyzes and accumulates opinions of anonymous experts. Opinions of the experts can be gained in different ways such as writing, discussion, feedback formats, etc. [29]. In this study, first, experts shared their knowledge, skills, opinions, and expertise until a mutual consensus was reached [30-33]. The method started with the selection of multiple anonymous experts and conducting a questionnaire survey with them for the first time. Then, the questionnaire survey was conducted for the second and third times. This step was repeated until a consensus was reached. Finally, opinions of the expert were integrated to achieve a consensus. The number of experts in the decision making group should not be too large or too small (between 5 and 50) [34]. The interviews were conducted with 17 anonymous experts from three different NGOs in Turkey in this study. It should be noted that experts were experienced in humanitarian relief operations.

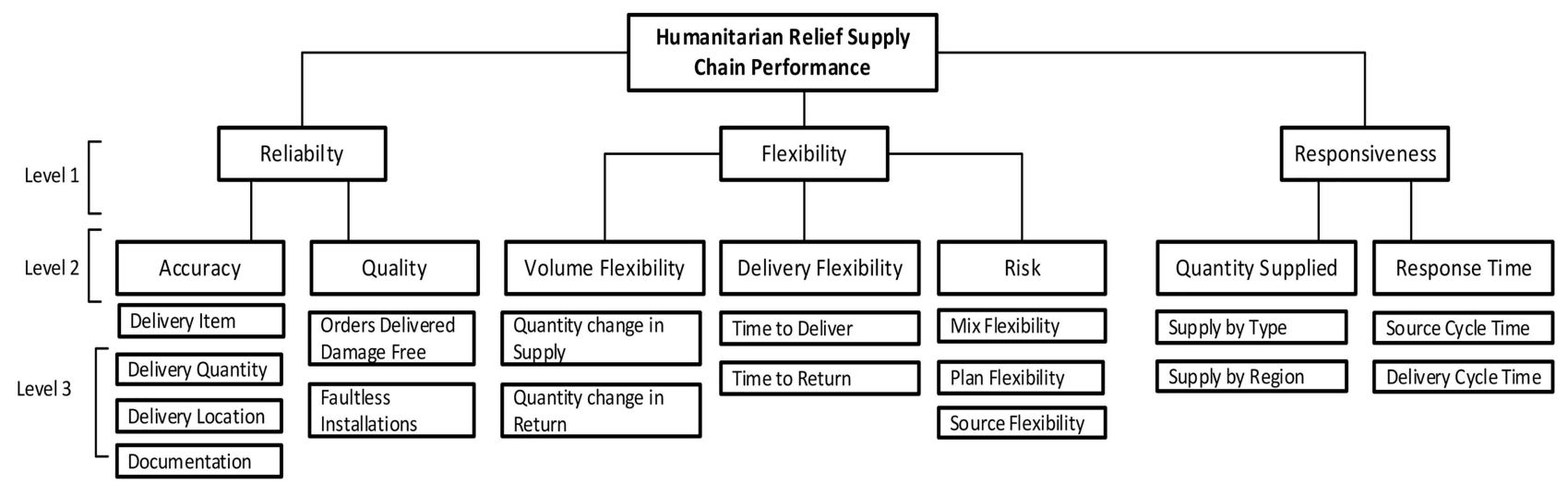

Figure 4. The proposed humanitarian relief SCOR model. 


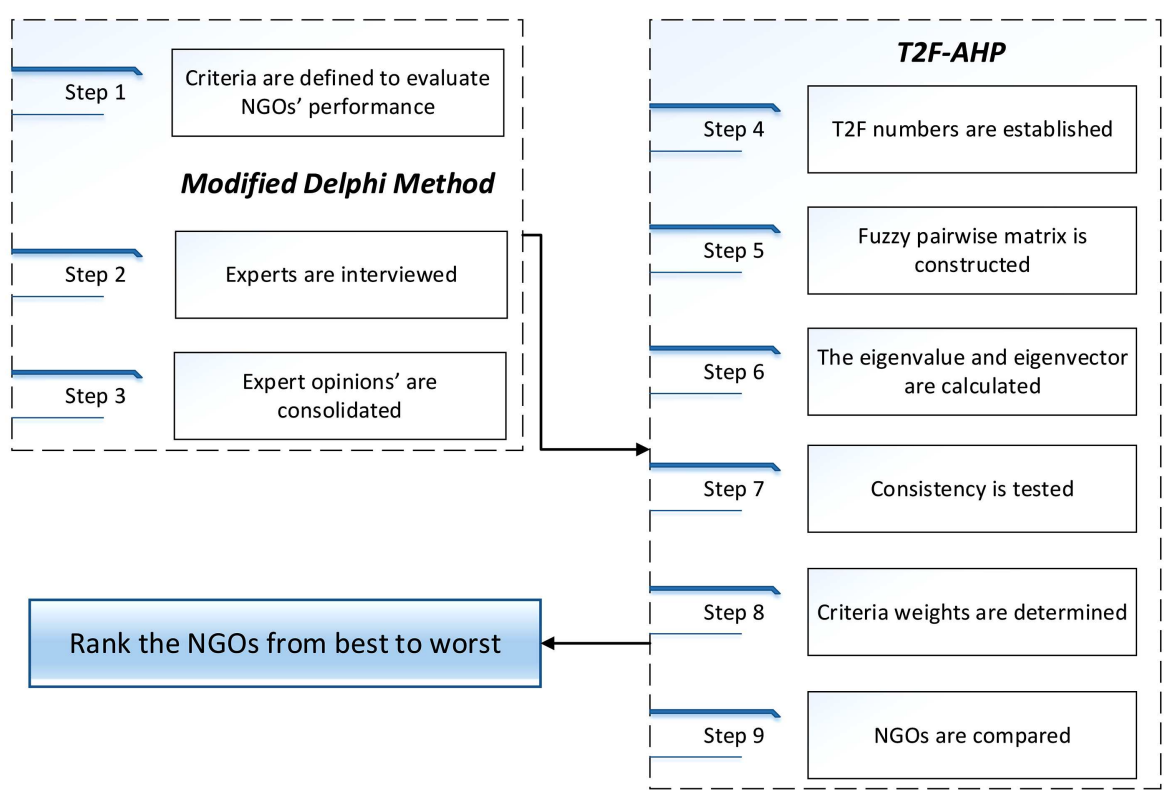

Figure 5. The proposed methodology.

\subsection{Trapezoidal T2F-AHP}

AHP is a mathematical approach first introduced in 1968 by Myers and Alpert [35]. However, the method was developed by Saaty in the 1970s and has become one of the most frequently used MCDM methods [36]. AHP allows the decision maker to include expert opinions and judgments in the evaluation process using linguistic terms, in addition to factor comparisons defined on a numerical scale. In this study, the 1-9 scale introduced by Saaty was used to convert non-numerical judgments into numerical data and the importance of each criterion could be shown on a numerical scale [37]. Furthermore, the AHP method allows all factors affecting the decision-making process to be ranked hierarchically within the framework of their relative importance. Therefore, complex decisionmaking problems can be easily solved by applying AHP. However, the method, which is applied by getting information from experts, sometimes fails to reflect the humanitarian way of thinking [38]. AHP was integrated with Fuzzy Logic (FL) to tackle this problem, called the fuzzy AHP [39]. FL was introduced by Zadeh in 1965 [40]. FL is a useful tool representing both qualitative assessment and subjective judgment in decision making. Using linguistic terms is an appropriate approach to handling uncertainty in assessments and judgments [41]. Trapezoidal fuzzy sets were used in this study to better represent the fuzzy set membership of the elements. These sets had both mathematical traceability and simplicity [42-45].

AHP can be integrated with T2F sets to better handle vagueness and uncertainty. Çelik et al. identified and evaluated the success factors for managing a humanitarian supply chain using T2F-AHP methodology [46]. Alegoz and Yapicioglu handled the problem of supplier selection in a fuzzy environment. They developed a hybrid methodology based on the T2F-AHP, fuzzy Technique for Order Preference by Similarity to an Ideal Solution (TOPSIS), and goal programming [47]. Yildiz et al. presented a T2FAHP methodology to prioritize public expectations from water treatment plants [48]. Ayyildiz et al. proposed a T2F-AHP integrated with a T2F Elimination and Choice Expressing the Reality (ELECTRE)-based model for individual credit ranking [45]. Abbasimehr and Tarokh developed interval type 2 AHP TOPSIS methodology to evaluate online community reviewers. The criteria weights were determined by interval type 2 AHP and reviewers were ranked by TOPSIS [49].

Some definitions about $\mathrm{T} 2 \mathrm{~F}$ sets are given and the combined AHP and T2F approach is briefly described in this section.

Definition 1. The fuzzy set is a set of objects with membership levels between 0 and 1 . If the membership value of an element equals 1 , it completely belongs to the fuzzy set. On the contrary, if a membership value equals 0 , it completely does not belong to the fuzzy set. The membership function of the T2F number " $m$ " is represented by $m=(a, b, c, d)$ :

$$
\mu_{m}(x)=\left\{\begin{array}{l}
\frac{x-a}{b-a} \quad \text { if } \quad a \leq x<b \\
1 \quad \text { if } \quad b \leq x \leq c \\
\frac{d-x}{d-c} \quad \text { if } \quad c<x \leq d
\end{array}\right.
$$

Here, " $a$ " is the lower limit of " $m$ ", " $[b, c]$ " is a mode interval of " $m$ ", and " $d$ " is the upper limit of " $m$ " [50].

Definition 2. A T2F set is defined by a membership function in the $X$ universe as follows: 


$$
\begin{aligned}
\tilde{\tilde{A}}= & \left\{\left((x, u), \mu_{\tilde{A}}(x, u)\right) \mid \forall x \in X, \forall u \in J_{x} \subseteq[0,1],\right. \\
& \left.0 \leq \mu_{\tilde{A}}(x, u) \leq 1\right\} .
\end{aligned}
$$

Let $J_{x}$ denote an interval in $[0,1]$. Also, the T2F set $\tilde{\tilde{A}}$ can be represented as given below:

$$
\tilde{\tilde{A}}=\int_{x \in X} \int_{u \in J_{x}} \frac{\mu_{\tilde{A}}(x, u)}{(x, u)} \quad \text { where } \quad J_{x} \subseteq[0,1],
$$

$J_{x}$ represents union over all valid $u$ and $x[45]$.

Definition 3. Both lower and upper membership functions of a T2F set membership functions of Type- 1 .

$$
\begin{aligned}
\tilde{\tilde{A}}_{i} & =\left(\tilde{A}_{i}^{U}, \tilde{A}_{i}^{L}\right) \\
& =\left(\left(a_{i 1}^{U}, a_{i 2}^{U}, a_{i 3}^{U}, a_{i 4}^{U} ; H_{1}\left(\tilde{A}_{i}^{U}\right), H_{2}\left(\tilde{A}_{i}^{U}\right)\right),\right. \\
& \left.\left(a_{i 1}^{L}, a_{i 2}^{L}, a_{i 3}^{L}, a_{i 4}^{L} ; H_{1}\left(\tilde{A}_{i}^{L}\right), H_{2}\left(\tilde{A}_{i}^{L}\right)\right)\right),
\end{aligned}
$$

where $\tilde{A}_{i}^{U}$ and $\tilde{A}_{i}^{L}$ are fuzzy sets, $a_{i 1}^{U}, a_{i 2}^{U}, a_{i 3}^{U}, a_{i 4}^{U}, a_{i 1}^{L}$, $a_{i 2}^{L}, a_{i 3}^{L}$, and $a_{i 4}^{L}$ are reference points of the T2F $\tilde{\tilde{A}}_{i}$, $H_{1}\left(\tilde{A}_{i}^{U}\right), H_{2}\left(\tilde{A}_{i}^{U}\right)$ represent the membership value of the element $a_{i(j+1)}^{U}$ in the upper function $\tilde{A}_{i}^{U}, H_{1}\left(\tilde{A}_{i}^{L}\right)$, and $H_{2}\left(\tilde{A}_{i}^{L}\right)$ represent the membership value of the element $a_{i(j+1)}^{L}$ in the upper function $\tilde{A}_{i}^{L}$. A T2F number is shown in Figure 6.

Sari et al. [51] and Kahraman et al. [52] presented the first studies to integrate Buckley's fuzzy AHP with T2F. The steps of the proposed T2F-AHP methodology are [45]:

Step 1: The MCDM problem and the criteria related to this problem are defined.

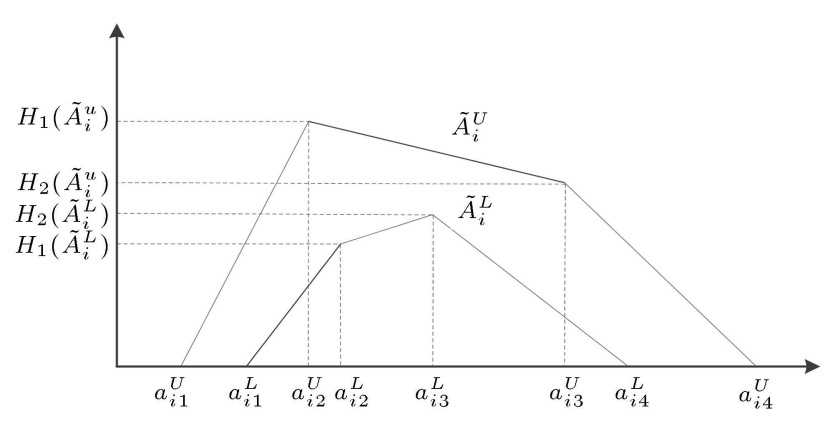

Figure 6. T2F membership function.

Step 2: A pairwise comparison matrix is constructed using the linguistic terms given in Table 1 by experts.

Step 3: The pairwise comparison matrix is tested for consistency. Crisp values are used to find the Consistency Ratio (CR) [36]:

$$
\begin{aligned}
& C I=\frac{\lambda_{\max }-n}{n-1} \quad \text { where } \quad \lambda_{\max }=\frac{A_{w}}{w}, \\
& C R=\frac{C I}{R I} .
\end{aligned}
$$

The Random Index (RI) is determined based on the matrix order [36]. CR must be smaller than 0.1 to be considered as consistent.

Step 4: Geometric mean is calculated for each criterion as follows:

$$
\tilde{\tilde{r}}_{i}=\left(\tilde{\tilde{a}}_{i 1} \otimes \tilde{\tilde{a}}_{i 2} \otimes \ldots \otimes \tilde{\tilde{a}}_{i n}\right)^{(1 / n)},
$$

where:

$$
\begin{aligned}
& \sqrt[n]{\tilde{\tilde{a}}_{i 1}}= \\
& \left(\left(\sqrt[n]{a_{i j 4}^{U}}, \sqrt[n]{a_{i j 3}^{U}}, \sqrt[n]{a_{i j 2}^{U}}, \sqrt[n]{a_{i j 1}^{U}} ; H_{1}\left(\tilde{\tilde{a}}_{i j}^{U}\right), H_{2}\left(\tilde{\tilde{a}}_{i j}^{U}\right)\right),\right. \\
& \left.\left(\sqrt[n]{a_{i j 4}^{L}}, \sqrt[n]{a_{i j 3}^{L}}, \sqrt[n]{a_{i j 2}^{L}}, \sqrt[n]{a_{i j 1}^{L}} ; H_{1}\left(\tilde{\tilde{a}}_{i j}^{L}\right), H_{2}\left(\tilde{\tilde{a}}_{i j}^{L}\right)\right)\right)
\end{aligned}
$$

Table 1. Definitions and related T2F numbers of the linguistic terms.

\begin{tabular}{lll}
\hline Linguistic terms & & \multicolumn{1}{c}{ T2F numbers } \\
\hline Absolutely weak & AW & $((0.1 ; 0.11 ; 0.11 ; 0.13 ; 1 ; 1),(0.11 ; 0.11 ; 0.11 ; 0.12 ; 0.9 ; 0.9))$ \\
Very Weak & VW & $((0.13 ; 0.14 ; 0.14 ; 0.17 ; 1 ; 1),(0.13 ; 0.14 ; 0.14 ; 0.15 ; 0.9 ; 0.9))$ \\
Fairly Weak & FW & $((0.17 ; 0.2 ; 0.2 ; 0.25 ; 1 ; 1),(0.18 ; 0.2 ; 0.2 ; 0.22 ; 0.9 ; 0.9))$ \\
Slightly Weak & SW & $((0.25 ; 0.33 ; 0.33 ; 0.5 ; 1 ; 1),(0.22 ; 0.33 ; 0.33 ; 0.4 ; 0.9 ; 0.9))$ \\
Equal & E & $((1 ; 1 ; 1 ; 1 ; 1 ; 1),(1 ; 1 ; 1 ; 1 ; 0.9 ; 0.9))$ \\
Slightly Strong & SS & $((2 ; 3 ; 3 ; 4 ; 1 ; 1),(2.5 ; 3 ; 3 ; 4.5 ; 0.9 ; 0.9))$ \\
Fairly Strong & FS & $((4 ; 5 ; 5 ; 6 ; 1 ; 1),(4.5 ; 5 ; 5 ; 5.5 ; 0.9 ; 0.9))$ \\
Very Strong & VS & $((6 ; 7 ; 7 ; 8 ; 1 ; 1),(6.5 ; 7 ; 7 ; 7.5 ; 0.9 ; 0.9))$ \\
Absolutely Strong & AS & $((8 ; 9 ; 9 ; 10 ; 1 ; 1),(8.5 ; 9 ; 9 ; 9.5 ; 0.9 ; 0.9))$ \\
\hline
\end{tabular}


Step 5: The fuzzy weight of each criterion is calculated by:

$$
\tilde{\tilde{w}}_{i}=\tilde{\tilde{r}}_{i} \otimes\left(\tilde{\tilde{r}}_{1} \oplus \tilde{\tilde{r}}_{2} \oplus \ldots \oplus \tilde{\tilde{r}}_{n}\right)^{-1}
$$

Step 6: T2F sets are defuzzified to determine the crisp importance weights:

$$
\begin{aligned}
w_{i}^{\prime}= & \frac{1}{2}\left(\frac{1}{2} \sum_{i=1}^{4}\left(a_{i}^{L}+\mathrm{a}_{\mathrm{i}}^{\mathrm{U}}\right)\right) \otimes \\
& \frac{1}{4}\left(\sum_{i=1}^{2}\left(H_{i}\left(A^{L}\right)+H_{i}\left(A^{U}\right)\right)\right) .
\end{aligned}
$$

Step 7: Crisp weights are normalized:

$$
w_{i}=\frac{w_{i}^{\prime}}{\sum_{i=1}^{n} w_{i}^{\prime}} .
$$

\section{Application to Turkey}

The importance weight of each criterion for performance evaluation of NGOs was obtained by using the interval T2F-AHP method. The opinions of 17 experts on these criteria were collected to evaluate the performance of three NGOs operating in Turkey as the most active ones in HRSC operations. Face to face interviews were conducted and questionnaires were distributed to the experts based on the modified Delphi method to gather their ideas on HRSC performance criteria and the NGO alternatives.

\subsection{Determination of criteria weights}

The experts employed a nine-point scale, as shown in Table 1, to evaluate the criteria and alternatives.

First, pairwise comparisons of the main criteria defined as SCOR Level 1 were evaluated by the experts using linguistics variables. Table 2 gives the consolidated pairwise comparison matrix of the Level 1 criteria. Then, for each SCOR Level 1 criterion, pairwise comparison was conducted with the respective SCOR Level 2 criterion. Then, for each SCOR Level 2 criterion, pairwise comparison with the respective SCOR Level 3 criterion was performed. In this way, a pairwise comparison matrix was constructed for all the criteria. CR was computed for each matrix and all the matrices were determined as consistent. Then, the importance weights for the Level 1, Level
2, and Level 3 criteria were determined. Consolidated pairwise comparison matrices for all the Level 1, Level 2 , and Level 3 criteria in a hierarchical structure were constructed. Subsequently, the T2F weight of each criterion was determined, as shown in Table 3 .

Fuzzy criteria weights were defuzzified and normalized, and the final weight for each criterion was determined. The final weights of the Level 1, Level 2, and Level 3 criteria are determined as shown in Table 4.

As seen from the Table 4, the weights of the three main criteria, namely, Reliability, Flexibility, and Responsiveness were obtained as $0.44,0.24$, and 0.32 , respectively. Accordingly, the most important factor for performance evaluation of the NGOs is Reliability with the rate of $44 \%$. Also, the results show that Responsiveness has the least importance weight for performance evaluation with the rate of $24 \%$. Among the Level 2 criteria, it can be seen that Quality is the most important factor with the highest importance rate of $28 \%$, that is, Quality has higher impact on the performance of the whole system than the other Level 2 criteria. Response Time is also an important criterion for performance evaluation at $19 \%$. Then, Accuracy and Quantity Supplied must be taken into account for the decisions on corporate strategy.

In the case of Reliability, it appears that Quality is almost twice as important as Accuracy. Looking at the Flexibility as a Level 1 criterion, it appears that the weight of its Level 2 criterion is very close to it. For the Level 1 criterion of Responsiveness, Response Time has $61 \%$ importance rate and Quantity Supplied has $39 \%$ importance rate. Finally, for the Level 3 criteria, it can be seen that Orders Delivered Damage Free has the highest weight with the importance rate of $17 \%$, which means that damage-free products play the key role for people who need aid. There are two other factors which have importance rates higher than 10\%; the first one is Source Cycle Time and the second is Faultless Installations. They are also significant for performance evaluation. Also, the least important criteria are Quantity Change in Return, Time to Return, Mix Flexibility, and Plan Flexibility with importance rates less than $3 \%$.

\subsection{Comparison of alternatives}

Three NGOs that operated in Turkey were selected for the evaluation of their HRSC performances as a real case study to prove validity and applicability of

Table 2. Pairwise comparison matrix for Level 1 criteria.

\begin{tabular}{llll}
\hline & Reliability & Flexibility & Responsiveness \\
\hline Reliability & Equal & Very strong & Slightly strong \\
Flexibility & Very weak & Equal & Very weak \\
Responsiveness & Slightly weak & Very strong & Equal \\
\hline
\end{tabular}


Table 3. Type-2 fuzzy weights of Level 1, Level 2, and Level 3 criteria.

\begin{tabular}{|c|c|c|}
\hline Level & Criterion & T2F numbers \\
\hline \multirow{3}{*}{ 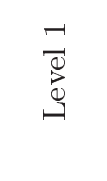 } & Reliability & $((0.452 ; 0.6336 ; 0.6336 ; 0.8617 ; 1 ; 1),(0.5388 ; 0.6336 ; 0.6336 ; 0.7581 ; 0.9 ; 0.9))$ \\
\hline & Flexibility & $((0.0494 ; 0.0628 ; 0.0628 ; 0.0822 ; 1 ; 1),(0.0555 ; 0.0628 ; 0.0628 ; 0.0732 ; 0.9 ; 0.9))$ \\
\hline & Accuracy & $((0.226 ; 0.3036 ; 0.3036 ; 0.4309 ; 1 ; 1),(0.2396 ; 0.3036 ; 0.3036 ; 0.3679 ; 0.9 ; 0.9))$ \\
\hline \multirow{7}{*}{$\begin{array}{l}\mathcal{N} \\
\mathbb{D} \\
\stackrel{D}{0} \\
\mapsto\end{array}$} & (Reliability) accuracy & $((0.1398 ; 0.1667 ; 0.1667 ; 0.2073 ; 1 ; 1),(0.1508 ; 0.1667 ; 0.1667 ; 0.1843 ; 0.9 ; 0.9))$ \\
\hline & Quality & $((0.6781 ; 0.8333 ; 0.8333 ; 1.0154 ; 1 ; 1),(0.7538 ; 0.8333 ; 0.8333 ; 0.9213 ; 0.9 ; 0.9))$ \\
\hline & Volume flexibility & $((0.1863 ; 0.2205 ; 0.2205 ; 0.2746 ; 1 ; 1),(0.1855 ; 0.2205 ; 0.2205 ; 0.2488 ; 0.9 ; 0.9))$ \\
\hline & Delivery flexibility & $((0.2958 ; 0.3192 ; 0.3192 ; 0.346 ; 1 ; 1),(0.3072 ; 0.3192 ; 0.3192 ; 0.3377 ; 0.9 ; 0.9))$ \\
\hline & Risk & $((0.3726 ; 0.4603 ; 0.4603 ; 0.5493 ; 1 ; 1),(0.4169 ; 0.4603 ; 0.4603 ; 0.5128 ; 0.9 ; 0.9))$ \\
\hline & Quantity supplied & $((0.1847 ; 0.2491 ; 0.2491 ; 0.3694 ; 1 ; 1),(0.1874 ; 0.2491 ; 0.2491 ; 0.3085 ; 0.9 ; 0.9))$ \\
\hline & Response time & $((0.5224 ; 0.7509 ; 0.7509 ; 1.0448 ; 1 ; 1),(0.6316 ; 0.7509 ; 0.7509 ; 0.9125 ; 0.9 ; 0.9))$ \\
\hline \multirow{17}{*}{ 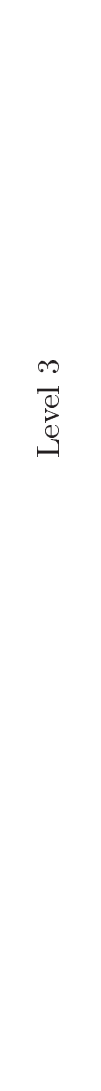 } & Delivery item accuracy & $((0.331 ; 0.3591 ; 0.3591 ; 0.3858 ; 1 ; 1),(0.3454 ; 0.3591 ; 0.3591 ; 0.3728 ; 0.9 ; 0.9))$ \\
\hline & Delivery quantity accuracy & $((0.1503 ; 0.1606 ; 0.1606 ; 0.1743 ; 1 ; 1),(0.1545 ; 0.1606 ; 0.1606 ; 0.1667 ; 0.9 ; 0.9))$ \\
\hline & Delivery location accuracy & $((0.2341 ; 0.2401 ; 0.2401 ; 0.2465 ; 1 ; 1),(0.2372 ; 0.2401 ; 0.2401 ; 0.2434 ; 0.9 ; 0.9))$ \\
\hline & Documentation accuracy & $((0.2341 ; 0.2401 ; 0.2401 ; 0.2465 ; 1 ; 1),(0.2372 ; 0.2401 ; 0.2401 ; 0.2434 ; 0.9 ; 0.9))$ \\
\hline & Orders del. damage free & $((0.6336 ; 0.7956 ; 0.7956 ; 0.9798 ; 1 ; 1),(0.7124 ; 0.7956 ; 0.7956 ; 0.9054 ; 0.9 ; 0.9))$ \\
\hline & Faultless installations & $((0.1584 ; 0.2044 ; 0.2044 ; 0.2828 ; 1 ; 1),(0.1575 ; 0.2044 ; 0.2044 ; 0.2442 ; 0.9 ; 0.9))$ \\
\hline & Quantity change in supply & $((0.8029 ; 0.9005 ; 0.9005 ; 1.0056 ; 1 ; 1),(0.8503 ; 0.9005 ; 0.9005 ; 0.9492 ; 0.9 ; 0.9))$ \\
\hline & Quantity change in return & $((0.0898 ; 0.0995 ; 0.0995 ; 0.1147 ; 1 ; 1),(0.0967 ; 0.0995 ; 0.0995 ; 0.1067 ; 0.9 ; 0.9))$ \\
\hline & Time to deliver & $((0.8029 ; 0.9005 ; 0.9005 ; 1.0056 ; 1 ; 1),(0.8503 ; 0.9005 ; 0.9005 ; 0.9492 ; 0.9 ; 0.9))$ \\
\hline & Time to return & $((0.0898 ; 0.0995 ; 0.0995 ; 0.1147 ; 1 ; 1),(0.0967 ; 0.0995 ; 0.0995 ; 0.1067 ; 0.9 ; 0.9))$ \\
\hline & Mix flexibility & $((0.0872 ; 0.1044 ; 0.1044 ; 0.1323 ; 1 ; 1),(0.0961 ; 0.1044 ; 0.1044 ; 0.117 ; 0.9 ; 0.9))$ \\
\hline & Plan flexibility & $((0.2691 ; 0.3331 ; 0.3331 ; 0.4145 ; 1 ; 1),(0.2997 ; 0.3331 ; 0.3331 ; 0.3716 ; 0.9 ; 0.9))$ \\
\hline & Source flexibility & $((1.2322 ; 1.4829 ; 1.4829 ; 1.7862 ; 1 ; 1) \cdot(1.3534 ; 1.4829 ; 1.4829 ; 1.6286 ; 0.9 ; 0.9))$ \\
\hline & Supply by type & $((0.6781 ; 0.8333 ; 0.8333 ; 1.0154 ; 1 ; 1),(0.7538 ; 0.8333 ; 0.8333 ; 0.9213 ; 0.9 ; 0.9))$ \\
\hline & Supply by region & $((0.1398 ; 0.1667 ; 0.1667 ; 0.2073 ; 1 ; 1),(0.1508 ; 0.1667 ; 0.1667 ; 0.1843 ; 0.9 ; 0.9))$ \\
\hline & Source cycle time & $((0.6781 ; 0.8333 ; 0.8333 ; 1.0154 ; 1 ; 1),(0.7538 ; 0.8333 ; 0.8333 ; 0.9213 ; 0.9 ; 0.9))$ \\
\hline & Delivery cycle time & $((0.1398 ; 0.1667 ; 0.1667 ; 0.2073 ; 1 ; 1),(0.1508 ; 0.1667 ; 0.1667 ; 0.1843 ; 0.9 ; 0.9))$ \\
\hline
\end{tabular}

the proposed methodology. The organizations were listed alphabetically as Caritas Turkey, Humanitarian Relief Foundation, and Turkish Red Crescent. Only the names of the NGOs are mentioned due to privacy considerations and in the final ranking, NGO-1, NGO2, and NGO-3 are used instead of the names.
The determined weights of criteria by the T2FAHP were used to compare alternatives. The T2FAHP method was executed to evaluate alternatives again. By following the T2F-AHP steps and calculations, the three NGOs were ranked. The results and order of NGOs can be seen in Table 5 . 
Table 4. Global weights for Level 1, Level 2, and Level 3 criteria.

\begin{tabular}{|c|c|c|c|c|c|c|}
\hline $\begin{array}{c}\text { Level } 1 \text { criteria } \\
\text { and weights }\end{array}$ & $\begin{array}{c}\text { Level } 2 \text { criteria } \\
\text { and weights }\end{array}$ & $\mathbf{L W}^{\mathbf{a}}$ & $\mathbf{G} \mathbf{W}^{\mathrm{b}}$ & $\begin{array}{c}\text { Level } 3 \text { criteria } \\
\text { and weights }\end{array}$ & LW & GW \\
\hline \multirow{6}{*}{ Reliability (0.437) } & \multirow{4}{*}{ Accuracy } & \multirow{4}{*}{0.353} & \multirow{4}{*}{0.154} & Delivery item accuracy & 0.281 & 0.043 \\
\hline & & & & Delivery quantity accuracy & 0.225 & 0.035 \\
\hline & & & & Delivery location accuracy & 0.247 & 0.038 \\
\hline & & & & Documentation accuracy & 0.247 & 0.038 \\
\hline & \multirow{2}{*}{ Quality } & \multirow{2}{*}{0.647} & \multirow{2}{*}{0.283} & Orders del. damage free & 0.631 & 0.178 \\
\hline & & & & Faultless installations & 0.369 & 0.104 \\
\hline \multirow{5}{*}{ Reliability (0.240) } & \multirow{2}{*}{ Volume flexibility } & \multirow{2}{*}{0.294} & \multirow{2}{*}{0.079} & Time to deliver & 0.676 & 0.053 \\
\hline & & & & Time to return & 0.324 & 0.026 \\
\hline & \multirow{3}{*}{ Risk } & \multirow{3}{*}{0.378} & \multirow{3}{*}{0.091} & Mix flexibility & 0.237 & 0.021 \\
\hline & & & & Plan flexibility & 0.278 & 0.025 \\
\hline & & & & Source flexibility & 0.485 & 0.044 \\
\hline \multirow{4}{*}{ Responsiveness (0.323) } & \multirow{2}{*}{ Quantity supplied } & \multirow[t]{2}{*}{0.389} & \multirow[t]{2}{*}{0.126} & Supply by type & 0.647 & 0.081 \\
\hline & & & & Supply by region & 0.353 & 0.044 \\
\hline & \multirow{2}{*}{ Response time } & \multirow[t]{2}{*}{0.611} & \multirow[t]{2}{*}{0.197} & Source cycle time & 0.647 & 0.128 \\
\hline & & & & Delivery cycle time & 0.353 & 0.070 \\
\hline
\end{tabular}

a:LW: Local Weight; b:GW: Global Weights.

Table 5. Evaluation of three NGOs.

\begin{tabular}{lcccc}
\hline \multicolumn{1}{c}{ Level 3 criterion } & Weight & NGO-1 & NGO-2 & NGO-3 \\
\hline Delivery item accuracy & 0.043 & 0.333 & 0.333 & 0.333 \\
Delivery quantity accuracy & 0.035 & 0.333 & 0.333 & 0.333 \\
Delivery location accuracy & 0.038 & 0.333 & 0.333 & 0.333 \\
Documentation accuracy & 0.038 & 0.492 & 0.27 & 0.238 \\
Orders delivered damage free & 0.178 & 0.492 & 0.27 & 0.238 \\
Faultless installations & 0.104 & 0.491 & 0.27 & 0.24 \\
Quantity change in supply & 0.048 & 0.492 & 0.27 & 0.238 \\
Quantity change in return & 0.023 & 0.333 & 0.333 & 0.333 \\
Time to deliver & 0.053 & 0.476 & 0.278 & 0.247 \\
Time to return & 0.026 & 0.492 & 0.27 & 0.238 \\
Mix flexibility & 0.021 & 0.333 & 0.333 & 0.333 \\
Plan flexibility & 0.025 & 0.333 & 0.333 & 0.333 \\
Source flexibility & 0.044 & 0.492 & 0.27 & 0.238 \\
Supply by type & 0.081 & 0.333 & 0.333 & 0.333 \\
Supply by region & 0.044 & 0.492 & 0.27 & 0.238 \\
Source cycle time & 0.128 & 0.433 & 0.306 & 0.26 \\
Delivery cycle time & 0.07 & 0.491 & 0.27 & 0.24 \\
\hline AHP-score & - & 0.420 & 0.267 & 0.244 \\
Ranking & $\mathbf{1}$ & $\mathbf{2}$ & $\mathbf{3}$ \\
\hline
\end{tabular}


Table 6. The new weights of criteria after changing the weights of reliability and flexibility.

\begin{tabular}{|c|c|c|c|c|c|c|}
\hline $\begin{array}{c}\text { Level } 0 \\
\text { criteria and weights }\end{array}$ & $\begin{array}{c}\text { Level } 1 \\
\text { criteria and weights }\end{array}$ & $\mathbf{L W}$ & $\mathbf{G W}$ & $\begin{array}{c}\text { Level } 2 \\
\text { criteria and weights }\end{array}$ & LW & GW \\
\hline \multirow{6}{*}{ Reliability (0.240) } & \multirow{4}{*}{ Accuracy } & \multirow{4}{*}{0.353} & \multirow{4}{*}{0.085} & Delivery item accuracy & 0.281 & 0.024 \\
\hline & & & & Delivery quantity accuracy & 0.225 & 0.019 \\
\hline & & & & Delivery location accuracy & 0.247 & 0.021 \\
\hline & & & & Documentation accuracy & 0.247 & 0.021 \\
\hline & \multirow{2}{*}{ Quality } & \multirow{2}{*}{0.647} & \multirow{2}{*}{0.155} & Orders del. damage free & 0.631 & 0.098 \\
\hline & & & & Faultless installations & 0.369 & 0.057 \\
\hline \multirow{7}{*}{ Flexibility (0.437) } & \multirow{2}{*}{ Volume flexibility } & \multirow{2}{*}{0.294} & \multirow{2}{*}{0.128} & Quantity change in supply & 0.676 & 0.087 \\
\hline & & & & Quantity change in return & 0.324 & 0.042 \\
\hline & \multirow{2}{*}{ Delivery flexibility } & \multirow{2}{*}{0.328} & \multirow{2}{*}{0.143} & Time to deliver & 0.676 & 0.097 \\
\hline & & & & Time to return & 0.324 & 0.046 \\
\hline & \multirow{3}{*}{ Risk } & \multirow{3}{*}{0.378} & \multirow{3}{*}{0.165} & Mix flexibility & 0.237 & 0.039 \\
\hline & & & & Plan flexibility & 0.278 & 0.046 \\
\hline & & & & Source flexibility & 0.485 & 0.08 \\
\hline \multirow{5}{*}{ Responsiveness (0.323) } & \multirow{3}{*}{ Quantity supplied } & \multirow{3}{*}{0.389} & \multirow{3}{*}{0.126} & Supply by type & 0.647 & 0.081 \\
\hline & & & & Supply by region & 0.353 & 0.044 \\
\hline & & & & & & \\
\hline & \multirow{2}{*}{ Response time } & \multirow{2}{*}{0.611} & \multirow{2}{*}{0.197} & Source cycle time & 0.647 & 0.128 \\
\hline & & & & Delivery cycle time & 0.353 & 0.070 \\
\hline
\end{tabular}

As mentioned before, opinions of 17 experts on these criteria were collected to evaluate the performances of the three NGOs. First, the CRs for all the evaluations were calculated and determined, which were below 0.1 , proving their consistency. Then, the Turkish HRSC NGOs were compared according to the T2F-AHP scores. The ranking of the alternatives was translated into NGO-1, NGO-2, and NGO-3 from the best to the worst, that is, the best alternative was NGO-1 with the highest AHP score.

\subsection{Sensitivity analysis}

A sensitivity analysis was done to discuss and analyze the proposed methodology. For this aim, Level 1 criteria weights obtained by the T2F-AHP were changed while the other ones remained constant. That is, the weight of the first Level 1 criterion was replaced subsequently with the second and third Level 1 criteria, while the remaining ones were constant. This was done to the second and third criteria weights as well. Then, the criteria weights for Level 2 and Level 3 were recalculated. In this way, the behavior of the proposed methodology against weight changes was evaluated. The results help decision makers determine the priorities and follow a simpler analysis process. The results of the sensitivity analysis can be seen in Figure 7.

With mutual changes in the Level 1 criteria weights, the final ranking of the NGOs also changed. For example, considering the first criterion as Accuracy and the second one as Flexibility, the weights of the

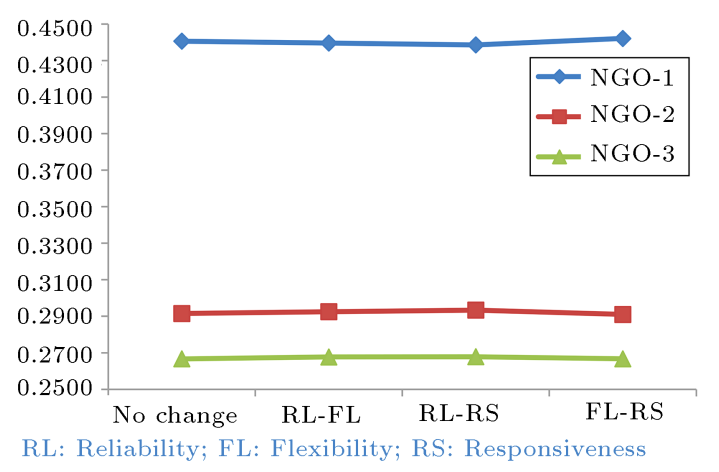

Figure 7. Changes in model results caused by the sensitivity analysis.

Level 1 criteria changed. The final score of the NGO-3 changed from 0.266 to 0.267 . Likewise, NGO-2 changed from 0.291 to 0.292 while NGO-1 decreases from 0.440 to 0.439 . It can be seen here that the weights of the NGOs got closer to each other. It can be seen that with change in the weights of the third criterion as Responsiveness and the second one as Flexibility, NGO1 became even more prominent.

With mutual change in the criteria weights of Level 1, the global weight of Level 2 criteria also changed. For example, considering the first criterion as Accuracy and the second one as Flexibility, the weights of the Level 1 criteria changed. Also, with decrease in the global weight of Delivery Item Accuracy from 0.043 to 0.024 , the global weight of Quantity Change in Supply also changed from 0.048 to 0.087 . Level 2 criteria weights can be seen in Table 6 and the scores 
Table 7. The new scores of NGOs after changing the weights of reliability and flexibility.

\begin{tabular}{lcccc}
\hline \multicolumn{1}{c}{ Criterion } & Weight & NGO-1 & NGO-2 & NGO-3 \\
\hline Delivery item accuracy & 0.024 & 0.333 & 0.333 & 0.333 \\
Delivery quantity accuracy & 0.019 & 0.333 & 0.333 & 0.333 \\
Delivery location accuracy & 0.021 & 0.333 & 0.333 & 0.333 \\
Documentation accuracy & 0.021 & 0.492 & 0.27 & 0.238 \\
Orders delivered damage free & 0.098 & 0.492 & 0.27 & 0.238 \\
Faultless installations & 0.057 & 0.491 & 0.27 & 0.24 \\
Quantity change in supply & 0.087 & 0.492 & 0.27 & 0.238 \\
Quantity change in return & 0.042 & 0.333 & 0.333 & 0.333 \\
Time to deliver & 0.097 & 0.476 & 0.278 & 0.247 \\
Time to return & 0.046 & 0.492 & 0.27 & 0.238 \\
Mix flexibility & 0.039 & 0.333 & 0.333 & 0.333 \\
Plan flexibility & 0.046 & 0.333 & 0.333 & 0.333 \\
Source flexibility & 0.080 & 0.492 & 0.27 & 0.238 \\
Supply by type & 0.081 & 0.333 & 0.333 & 0.333 \\
Supply by region & 0.044 & 0.492 & 0.27 & 0.238 \\
Source cycle time & 0.128 & 0.433 & 0.306 & 0.26 \\
Delivery cycle time & 0.070 & 0.491 & 0.27 & 0.24 \\
\hline Score & - & 0.440 & 0.292 & 0.268 \\
\hline
\end{tabular}

of the NGOs in Table 7 after changing the weight of reliability with the weight of flexibility.

\subsection{Comparative analysis}

The results of the proposed T2F-AHP methodology are compared with the results gained from the fuzzy Simple Additive Weighting (SAW) method. SAW is used in many different application areas generally as an alternative comparison methodology: instances are location selection [53], health record architectures identification [54], inventory model determination [55], network selection [56], outscore manufacturers evaluation [57], and strategic system selection [58]. The score of each alternative based on the fuzzy SAW method was calculated via Eq. (12):

$$
S_{j}=\sum_{k=1}^{K} \sum_{i=1}^{m} w_{i} x \operatorname{defuzzified}\left(\tilde{Y}_{i j}\right) .
$$

$\tilde{Y}_{i j}$ denotes the T2F evaluation of NGO $j$ for criterion $i$ and defuzzified $\left(\tilde{Y}_{i j}\right)$ denotes the defuzzified value of the assigned linguistic term to $\tilde{Y}_{i j}$. The linguistic terms are defuzzified using Eq. (10), as given in Table 8.

The alternative evaluation matrix was constructed using the defuzzified values. Table 9 shows both linguistic terms and their defuzzified values.

Then final score for each alternative was calculated via Eq. (12). According to the results, NGO-1 had the highest final score with 4.721. Then, NGO2 was the second best alternative with the final score of 2.668. The alternative with the lowest final score was NGO-3 with the final score of 1.335. Thus, the final ranking order is NGO-1 > NGO-2 > NGO-3.
Table 8. Defuzzified values of linguistic terms.

\begin{tabular}{lc}
\hline Linguistic term & Defuzzified value \\
\hline Absolutely weak & 0.107 \\
Very weak & 0.135 \\
Fairly weak & 0.192 \\
Slightly weak & 0.319 \\
Equal & 0.95 \\
Slightly strong & 2.909 \\
Fairly strong & 4.691 \\
Very strong & 6.65 \\
Absolutely strong & 8.55 \\
\hline
\end{tabular}

The ranking order is the same as the result of the proposed T2F-AHP methodology. However, defuzzification, which leads to the loss of some information, was not required in the proposed methodology.

\subsection{Managerial implications}

The findings obtained from the performance analysis of NGOs operating in Turkey were examined by six experts (two from NGOs, one from a governmental organization, and three academicians). All experts worked on the HRSC related subjects. They were asked to evaluate the acceptability and applicability of the results. First of all, experts were informed about the purpose of the proposed T2F-AHP methodology, mathematical expressions, and criteria. Then, they were asked to evaluate the results by comparing them with the current situation of NGOs. The general evaluation of the experts was that the findings obtained were consistent with the real situation. It was emphasized that the results for NGO-3 should be examined in more 
Table 9. Alternative evaluation matrix.

\begin{tabular}{lcccccc}
\hline Criterion & \multicolumn{2}{c}{ NGO-1 } & \multicolumn{2}{c}{ NGO-2 } & \multicolumn{2}{c}{ NGO-3 } \\
\hline Delivery item accuracy & E & 0.95 & E & 0.95 & E & 0.95 \\
Delivery quantity accuracy & E & 0.95 & E & 0.95 & E & 0.95 \\
Delivery location accuracy & E & 0.95 & E & 0.95 & E & 0.95 \\
Documentation accuracy & VS & 6.65 & SS & 2.91 & E & 0.95 \\
Orders delivered damage Free & VS & 6.65 & SS & 2.91 & E & 0.95 \\
Faultless installations & VS & 6.65 & SS & 2.91 & SW & 0.319 \\
Quantity change in supply & AS & 8.55 & FS & 4.69 & SS & 2.909 \\
Quantity change in return & E & 0.95 & E & 0.95 & E & 0.95 \\
Time to deliver & FS & 4.69 & SS & 2.91 & E & 0.95 \\
Time to return & VS & 6.65 & FS & 4.69 & SS & 2.909 \\
Mix flexibility & FS & 4.69 & FS & 4.69 & FS & 4.691 \\
Plan flexibility & FW & 0.19 & FW & 0.19 & FW & 0.192 \\
Source flexibility & FW & 0.19 & VW & 0.14 & VW & 0.135 \\
Supply by type & FS & 4.69 & FS & 4.69 & SS & 2.909 \\
Supply by region & VS & 6.65 & SS & 2.91 & E & 0.95 \\
Source cycle time & FS & 4.69 & SS & 2.91 & E & 0.95 \\
Delivery cycle time & VS & 6.65 & E & 0.95 & SW & 0.319 \\
\hline
\end{tabular}

detail. The performance of the NGOs was expected to increase in the coming years. The details of some evaluations made by experts are listed as follows:

- According to the study, NGO-1 is the best NGO among the three alternatives with both the proposed T2F-AHP and SAW. This is due to the fact that NGO-1 has better values for all criteria;

- NGO-3 has the lowest score. The reason is that NGO-3 has lower values for both Level 1 criteria of Flexibility and Responsiveness and their inner levels;

- All NGOs must improve their plans and source flexibility;

- Flexibility is the most important Level 1 criterion that NGOs must focus on;

- NGOs perform better in time related issues.

The consulted experts also made some suggestions for the implementation process. First, more effective evaluations could be made when income/cost parameters of NGOs were added. Another suggestion was that the analysis could be performed with more NGO alternatives. Finally, it was suggested that governmental organizations could be included in the methodology.

\section{Conclusion}

In this paper, performance evaluation problem of Humanitarian Relief Supply Chain (HRSC) was taken into account and considered as an Multi-Criteria Decision Making (MCDM) problem. 17 experts from three Turkish Non-Governmental Organizations (NGOs) were interviewed to determine the most important criteria for performance evaluation. Then, a novel hybrid Type-2 Fuzzy Analytic Hierarchy Process (T2F-AHP) methodology for Supply Chain Operations Reference (SCOR) was structured and the three NGOs were compared with the help of the proposed methodology. Also, a sensitivity analysis was performed to discuss the results of the proposed methodology. Finally, a comparative analysis was conducted to show robustness of the proposed methodology.

The contributions of the paper can be specified as follows: (1) the SCOR model was adopted for performance evaluation of the HRSC; (2) the most important factors on the HRSC performance were determined and classified; (3) the factors (Level 1) and their sub-factors (Level 2 and Level 3 ) were evaluated by the proposed T2F-AHP methodology and the weight of each factor (Level 1, Level 2, and Level 3) was determined; (4) a real case application was presented to show the reliability and applicability of the proposed methodology; (5) the proposed method can be used by governmental and NGOs to improve their HRSC strategies; (6) to the best of our knowledge, this study is the first real case for adopting the SCOR model in HRSC performance evaluation.

For a future direction, other fuzzy MCDM methods or heuristics can be included in the methodology 
to ensure more comparative and integrated study. Organizations in different countries can be compared using this work or the study can be expanded by dealing with more organizations.

\section{References}

1. Swamidass, P.M., Ed., "Seven rights of logistics", In Encyclopedia of Production and Manufacturing Management, Springer, US, Boston, MA, p. 684 (2000).

2. Beamon, B.M. and Balcik, B. "Performance measurement in humanitarian relief chains", Int. J. Public Sect. Manag., 21(1), pp. 4-25 (2008).

3. Mentzer, J.T., DeWitt, W., Keebler, J.S., et al. "Defining supply chain management", J. Bus. Logist., 22(2), pp. 1-25 (2001).

4. Chandraprakaikul, W. "Humanitarian supply chain management: literature review and future research", 2nd Int. Conf. Logist. Transp. Queenst (2010).

5. Ergun, O., Karakus, G., Keskinocak, P., et al. "Humanitarian supply chain management-an overview", Dagstuhl Semin. Proc., Schloss Dagstuhl-LeibnizZentrum für Informatik (2009).

6. Van Wassenhove, L.N. "Blackett memorial lecture humanitarian aid logistics: Supply chain management in high gear", J. Oper. Res. Soc., 57(5), pp. 475-489 (2006).

7. Oloruntoba, R. and Gray, R. "Humanitarian aid: An agile supply chain?", Supply Chain Manag., 11(2), pp. 115-120 (2006).

8. Sheu, J.B. "Challenges of emergency logistics management", Transp. Res. Part E Logist. Transp. Rev., 43(6), pp. 655-659 (2007).

9. Ge, Y., Gu, Y., and Deng, W. "Evaluating china's national post-disaster plans: The 2008 Wenchuan Earthquake's recovery and reconstruction planning", Int. J. Disaster Risk Sci., 1(2), pp. 17-27 (2010).

10. Khan, F.A. and Salman, A. "A simple human vulnerability index to climate change hazards for Pakistan", Int. J. Disaster Risk Sci., 3(3), pp. 163-176 (2012).

11. Özdamar, L. and Demir, O. "A hierarchical clustering and routing procedure for large scale disaster relief logistics planning", Transp. Res. Part E Logist. Transp. Rev., 48(3), pp. 591-602 (2012).

12. Alexander, B., Cox, L.J., and Mochizuki, J. "Integrated risk identification, analysis, and assessment: A dynamic household economy analysis methodology and example", Int. J. Disaster Risk Sci., 4(2), pp. 77-88 (2013).

13. Wang, H., Du, L., and Ma, S. "Multi-objective open location-routing model with split delivery for optimized relief distribution in post-earthquake", Transp. Res. Part E Logist. Transp. Rev., 69, pp. 160-179 (2014).

14. Liu, M., Cao, J., Liang, J., et al. "Logistics planning for hospital pharmacy trusteeship under a hybrid of uncertainties", In Epidemic-Logistics Modeling: A New Perspective on Operations Research, Springer Singapore, pp. 189-213 (2020).

15. Singh, A., Shukla, N., and Mishra, N. "Social media data analytics to improve supply chain management in food industries", Transp. Res. Part E Logist. Transp. Rev., 114, pp. 398-415 (2018).

16. Gharib, Z., Bozorgi-Amiri, A., Tavakkoli-Moghaddam, R., et al. "A cluster-based emergency vehicle routing problem in disaster with reliability", Sci. Iran., 25(4), pp. 2312-2330 (2018).

17. Balcik, B. and Beamon, B.M. "Facility location in humanitarian relief", Int. J. Logist. Res. Appl., 11(2), pp. 101-121 (2008).

18. Tatham, P. and Kovács, G. "The application of 'swift trust' to humanitarian logistics", Int. J. Prod. Econ., 126(1), pp. 35-45 (2010).

19. Blecken, A. "Supply chain process modelling for humanitarian organizations", Int. J. Phys. Distrib. Logist. Manag., 40(8), pp. 675-692 (2010).

20. Van Der Laan, E.A., De Brito, M.P., and Vergunst, D.A. "Performance measurement in humanitarian supply chains", Int. J. Risk Assess. Manag., 13(1), pp. 22-45 (2009).

21. Kabra, G. and Ramesh, A. "Analyzing drivers and barriers of coordination in humanitarian supply chain management under fuzzy environment", Benchmarking, 22(4), pp. 559-587 (2015).

22. Anjomshoae, A., Hassan, A., Kunz, N., et al. "Toward a dynamic balanced scorecard model for humanitarian relief organizations' performance management", J. Humanit. Logist. Supply Chain Manag., 7(2), pp. 194-218 (2017).

23. Lu, Q., Goh, M., and De Souza, R. "A SCOR framework to measure logistics performance of humanitarian organizations", J. Humanit. Logist. Supply Chain Manag., 6(2), pp. 222-239 (2016).

24. Laguna-Salvadó, L., Lauras, M., Okongwu, U., et al. "A multicriteria master planning DSS for a sustainable humanitarian supply chain", Ann. Oper. Res., 283(12), pp. 1303-1343 (2019).

25. Roh, S.Y., Jang, H.M., and Han, C.H. "Warehouse location decision factors in humanitarian relief logistics", Asian J. Shipp. Logist., 29(1), pp. 103-120 (2013).

26. Drakaki, M., Gören, H.G., and Tzionas, P. "An intelligent multi-agent based decision support system for refugee settlement siting", Int. J. Disaster Risk Reduct., 31, pp. 576-588 (2018).

27. Lockamy, A. and McCormack, K. "Linking SCOR planning practices to supply chain performance: An exploratory study", Int. J. Oper. Prod. Manag., 24(12), pp. 1192-1218 (2004).

28. Supply Chain Council, Supply Chain Operations Reference Model Version 10.0 (2010). 
29. Gumus, A.T. "Evaluation of hazardous waste transportation firms by using a two step fuzzy-AHP and TOPSIS methodology", Expert Syst. Appl., $\mathbf{3 6}(2$ PART 2), pp. 4067-4074 (2009).

30. Hartman, A. "Reaching consensus using the Delphi technique.", Educ. Leadersh., 38(6), pp. 495-97 (1981).

31. Sung, W.C. "Application of Delphi method, a qualitative and quantitative analysis, to the healthcare management", J. Healthc. Manag., 2(2), pp. 11-19 (2001).

32. Chang, C.W., Wu, C.R., and Chen, H.C. "Using expert technology to select unstable slicing machine to control wafer slicing quality via fuzzy AHP", Expert Syst. Appl., 34(3), pp. 2210-2220 (2008).

33. Hsu, P.F., Wu, C.R., and Li, Y.T. "Selection of infectious medical waste disposal firms by using the analytic hierarchy process and sensitivity analysis", Waste Manag., 28(8), pp. 1386-1394 (2008).

34. Robbins, S., Management, Prentice hall (1994).

35. Myers, J.H. and Alpert, M.I. "Determinant buying attitudes: Meaning and measurement", J. Mark., 32(4 part 1), pp. 13-20 (1968).

36. Saaty, T.L. "A scaling method for priorities in hierarchical structures", J. Math. Psychol., 15(3), pp. 234281 (1977).

37. Saaty, T.L. "How to handle dependence with the analytic hierarchy process", Math. Model., 9(3-5), pp. 369-376 (1987).

38. Ayyildiz, E. and Taskin Gumus, A. "A novel spherical fuzzy AHP-integrated spherical WASPAS methodology for petrol station location selection problem: a real case study for İstanbul", Environ. Sci. Pollut. Res., 27(29), pp. 36109-36120 (2020).

39. Yildiz, A., Ayyildiz, E., Taskin Gumus, A., et al. "A modified balanced scorecard based hybrid Pythagorean fuzzy AHP-topsis methodology for ATM site selection problem", Int. J. Inf. Technol. Decis. Mak., 19(02), pp. 365-384 (2020).

40. Zadeh, L.A. "Fuzzy sets", Inf. Control, 8(3), pp. 338353 (1965).

41. Wang, J.Q., Peng, J.J., Zhang, H.Y., et al. "An uncertain linguistic multi-criteria group decision-making method based on a cloud model", Gr. Decis. Negot., 24(1), pp. 171-192 (2015).

42. Bonissone, P.P. and Decker, K.S. "Selecting uncertainty calculi and granularity: An experiment in trading-off precision and complexity", In Machine Intelligence and Pattern Recognition, North-Holland, 4(C), pp. 217-247, January 1 (1986).

43. Wu, J.Y., Van Brunt, V., Zhang, W.R., et al. "Tower packing evaluation using linguistic variables", Comput. Math. with Appl., 15(10), pp. 863-869 (1988).

44. Dadone, P. and Vanlandingham, H.F. "Load transfer control for a gantry crane with arbitrary delay constraints", J. Vib. Control, 8(2), pp. 135-158 (2002).
45. Ayyildiz, E., Taskin Gumus, A., and Erkan, M. "Individual credit ranking by an integrated interval type-2 trapezoidal fuzzy electre methodology", Soft Comput, 24, pp. 16149-16163 (2020).

46. Çelik, E., Taskin Gumus, A., and Alegoz, M. "A trapezoidal type-2 fuzzy MCDM method to identify and evaluate critical success factors for humanitarian relief logistics management", J. Intell. Fuzzy Syst., 27(6), pp. 2847-2855 (2014).

47. Alegoz, M. and Yapicioglu, H. "Supplier selection and order allocation decisions under quantity discount and fast service options", Sustain. Prod. Consum., 18, pp. 179-189 (2019).

48. Yildiz, A., Ayyildiz, E., Taskin Gumus, A., et al. "A framework to prioritize the public expectations from water treatment plants based on trapezoidal Type-2 fuzzy Ahp method", Environ. Manage, 67, pp. 439448 (2021).

49. Abbasimehr, H. and Tarokh, M.J. "A novel interval type-2 fuzzy AHP-TOPSIS approach for ranking reviewers in online communities", Sci. Iran., 23(5), pp. 2355-2373 (2016).

50. Sadi-Nezhad, S. and Damghani, K.K. "Application of a fuzzy TOPSIS method base on modified preference ratio and fuzzy distance measurement in assessment of traffic police centers performance", Appl. Soft Comput. J., 10(4), pp. 1028-1039 (2010).

51. Sari, I.U., Behret, H., and Kahraman, C. "Risk governance of urban rail systems using fuzzy AHP: The case of Istanbul", Int. J. Uncertainty, Fuzziness KnowledgeBased Syst., World Scientific Publishing Company, pp. 67-79 (2012).

52. Kahraman, C., Sar, İ.U., and Turanoğlu, E. "Fuzzy analytic hierarchy process with Type-2 fuzzy sets", In Uncertainty Modeling in Knowledge Engineering and Decision Making, pp. 201-206 (October 2012).

53. Wang, Y.J. "A fuzzy multi-criteria decision-making model based on simple additive weighting method and relative preference relation", Appl. Soft Comput. J., 30, pp. 412-420 (2015).

54. Zandi, F. "A bi-level interactive decision support framework to identify data mining-oriented electronic health record architectures", Appl. Soft Comput. J., 18, pp. 136-145 (2014).

55. Sadeghi, J. and Niaki, S.T.A. "Two parameter tuned multi-objective evolutionary algorithms for a bi-objective vendor managed inventory model with trapezoidal fuzzy demand", Appl. Soft Comput. J., 30, pp. 567-576 (2015).

56. Goyal, R.K., Kaushal, S., and Sangaiah, A.K. "The utility based non-linear fuzzy AHP optimization model for network selection in heterogeneous wireless networks", Appl. Soft Comput. J., 67, pp. 800-811 (2018).

57. Kahraman, C., Öztayşi, B., and Çevik Onar, S. "An integrated intuitionistic fuzzy AHP and TOPSIS approach to evaluation of outsource manufacturers", J. Intell. Syst., 29(1), pp. 283-297 (2020). 
58. Zare Mehrjerdi, Y. "Strategic system selection with linguistic preferences and grey information using MCDM", Appl. Soft Comput. J., 18, pp. 323-337 (2014).

\section{Biographies}

Ertugrul Ayyildiz received PhD degree in Industrial Engineering from Yildiz Technical University in 2021. He received his MSc in Industrial Engineering from Karadeniz Technical University in 2017. He is now a Research Assistant at Karadeniz Technical University, Trabzon Turkey. His research interests includes mixed integer programming, location selection and fuzzy set.
He has published many papers in highly cited journals.

Alev Taskin received BSc and MSc degrees in Industrial Engineering from Yildiz Technical University in 2001 and 2003, respectively. She also received $\mathrm{PhD}$ degree in Industrial Engineering from the same university in 2007. She is now professor in Industrial Engineering at Yildiz Technical University. She has published many papers in highly cited journals such as Transportation Research Part E, Transportation Research Part A, Computers \& Industrial Engineering, International Journal of Production Research, Applied Soft Computing, etc. Her research interests are decision analysis, humanitarian logistics, and fuzzy sets. 